\title{
Very high MHC Class IIB diversity without spatial differentiation in the mediterranean population of greater Flamingos
}

Mark A. F. Gillingham ${ }^{1,2,3,4^{*}}$, Arnaud Béchet ${ }^{3}$, Alexandre Courtiol ${ }^{4,5}$, Manuel Rendón-Martos ${ }^{6}$, Juan A. Amat ${ }^{7}$, Boudjéma Samraoui ${ }^{9}, 10$, Ortaç Onmuş ${ }^{8}$, Simone Sommer ${ }^{1}$ and Frank Cézilly ${ }^{2,11}$

\begin{abstract}
Background: Selective pressure from pathogens is thought to shape the allelic diversity of major histocompatibility complex (MHC) genes in vertebrates. In particular, both local adaptation to pathogens and gene flow are thought to explain a large part of the intraspecific variation observed in MHC allelic diversity. To date, however, evidence that adaptation to locally prevalent pathogens maintains $\mathrm{MHC}$ variation is limited to species with limited dispersal and, hence, reduced gene flow. On the one hand high gene flow can disrupt local adaptation in species with high dispersal rates, on the other hand such species are much more likely to experience spatial variation in pathogen pressure, suggesting that there may be intense pathogen mediated selection pressure operating across breeding sites in panmictic species. Such pathogen mediated selection pressure operating across breeding sites should therefore be sufficient to maintain high MHC diversity in high dispersing species in the absence of local adaptation mechanisms. We used the Greater Flamingo, Phoenicopterus roseus, a long-lived colonial bird showing a homogeneous genetic structure of neutral markers at the scale of the Mediterranean region, to test the prediction that higher MHC allelic diversity with no population structure should occur in large panmictic populations of long-distance dispersing birds than in other resident species.

Results: We assessed the level of allelic diversity at the MHC Class IIB exon 2 from 116 individuals born in four different breeding colonies of Greater Flamingo in the Mediterranean region. We found one of the highest allelic diversity (109 alleles, 2 loci) of any non-passerine avian species investigated so far relative to the number of individuals and loci genotyped. There was no evidence of population structure between the four major Mediterranean breeding colonies.
\end{abstract}

Conclusion: Our results suggest that local adaptation at MHC Class IIB in Greater Flamingos is constrained by high gene flow and high MHC diversity appears to be maintained by population wide pathogen-mediated selection rather than local pathogen-mediated selection. Further understanding of how pathogens vary across space and time will be crucial to further elucidate the mechanisms maintaining MHC diversity in species with large panmictic populations and high dispersal rates.

Keywords: MHC genes, Allelic diversity, Pathogen-mediated balancing selection, Local adaptation, Greater flamingos

\footnotetext{
*Correspondence: Mark.Gillingham@uni-ulm.de

${ }^{1}$ University of Ulm, Institute of Evolutionary Ecology and Conservation

Genomics, Albert-Einstein Allee 11, D-89069 Ulm, Germany

${ }^{2}$ Université de Bourgogne, Equipe Ecologie Evolutive, UMR CNRS 6282

Biogéosciences, 6 bd. Gabriel, 21000 Dijon, France

Full list of author information is available at the end of the article
} 


\section{Background}

Genetic diversity is an essential component of the adaptive potential of populations $[1,2]$. The major histocompatibility $(\mathrm{MHC})$ genes code for glycoproteins which present antigens to T-cells playing an integral role in the adaptive immune response [3]. The MHC genes form a multigene family, and are known to be among the most polymorphic genes of the vertebrate genome, with most populations exhibiting a high level of MHC allelic diversity in terms of both allele number and sequence divergence $[4,5]$. This multigene family has therefore become an important model of adaptive variation in natural populations of vertebrates $[4,5]$.

The maintenance of MHC polymorphism is generally attributed to powerful pathogen-mediated balancing selection, with gene conversion and recombination, maternal-foetal interactions and sexual selection also thought to play a role $[4,5]$. Since selection from local pathogens may be sufficiently strong to change MHC allele frequencies within the short evolutionary time of a few generations [6-8], we can expect local pathogenmediated selection at the MHC to be stronger than either neutral forces (such as gene flow and genetic drift) or pathogen-mediated selection at the scale of the metapopulation. Such local pathogen-mediated selection can occur if there is spatial and temporal variation in pathogen-mediated selection ("fluctuating selection") [9] and/or local cyclical selection between host and pathogen ("negative frequency-dependent selection") [10-12], and both mechanisms are thought to play a crucial role in maintaining $\mathrm{MHC}$ diversity. Indeed, stronger population structure at the MHC than at neutral markers have been demonstrated in numerous species that show some level of population structure at neutral markers (reviewed in [5]). However, the occurrence of local adaptation at the $\mathrm{MHC}$ in species with high gene flow remains to be investigated.

Long-lived and dispersing species with large geographical distributions, often associated with panmixia at neutral markers, face a particular challenge: individuals are likely to encounter during their life heterogeneous environmental conditions, each associated with distinct pathogen communities [13]. Indeed, species that are migratory $[14,15]$ and have large geographical distributions $[14,16,17]$ are known to have more diverse parasitic communities. As a consequence of encountering more diverse parasitic communities, migratory or long-distance dispersing species may be under more intense pathogen mediated selection than resident species. In support of the latter, a recent comparative study has found that the rate of non-synonymous nucleotide substitution across the antigen binding regions of the MHC class IIB (a signal of balancing selection) is significantly higher in migratory species [18]. The latter study also found that colonial species had a higher rate of non-synonymous nucleotide substitution, which suggests that the high contact between conspecifics in colonial species leads to elevated transmission rates and therefore increased balancing selection of MHC genes [18]. However, the high gene flow of high dispersing species is likely to disrupt local adaptation and other pathogen-mediated balancing selection mechanisms are likely to be maintaining MHC diversity. For instance, frequency-dependent selection may be operating across breeding sites in panmictic species. Another non-mutually exclusive hypothesis, which could also be operating across breeding sites in panmictic species, is the "overdominant heterozygote advantage" hypothesis. The latter proposes that MHC heterozygotes will be fitter than the fittest MHC homozygote because they will be able to recognize a greater diversity of parasites [19, 20]. Higher MHC allelic diversity can thus be expected in colonial and longdistance dispersing species with little or no spatial differentiation between breeding sites than locally adapted resident species, based on the idea that higher pathogenmediated balancing selection is operating across breeding sites in panmictic species. In addition, such long-range dispersing species should have no MHC population structure since gene flow prevents local adaptation.

To investigate MHC diversity and population structure in a long-lived colonial species with high gene flow, we used data from Gillingham et al. [21], which genotyped MHC Class IIB exon 2 of 116 Greater Flamingos across four breeding colonies spread across the entire range of the species in the Mediterranean basin (Fig. 1). Non-random patterns of natal and breeding dispersal between breeding colonies has been shown by capture-markrecapture studies [22], which may favour local divergent adaptations [23]. However, molecular data on 13 microsatellite loci and two mitochondrial markers were consistent with strong gene flow and a panmictic genetic structure of the population at the scale of the Mediterranean basin [24].

\section{Methods \\ Samples}

Samples were collected between 1998 and 2009, at four breeding colonies across the Mediterranean basin breeding range (Table 1; Fig. 1): Garaet Ezzemoul, northern Algeria $\left(35^{\circ} 53^{\prime} \mathrm{N}, 06^{\circ} 30^{\prime} \mathrm{E}\right)$; Camargue, southern France $\left(43^{\circ} 25^{\prime} \mathrm{N}, 04^{\circ} 38^{\prime} \mathrm{E}\right)$; Fuente de Piedra, southern Spain $\left(37^{\circ} 06^{\prime} \mathrm{N}, 04^{\circ} 45^{\circ} \mathrm{W}\right)$; and Gediz Delta, western Turkey $\left(38^{\circ} 32^{\prime} \mathrm{N}, 26^{\circ} 52^{\prime} \mathrm{E}\right)$.

\section{MHC Class IIB exon2 genotyping}

Details of MHC Class IIB exon 2 genotyping can be found in Gillingham et al. [21] which genotyped the individuals used in this study using barcoded PCRs in 454 Titanium pyrosequencing run. Briefly, 163-165 bp of 


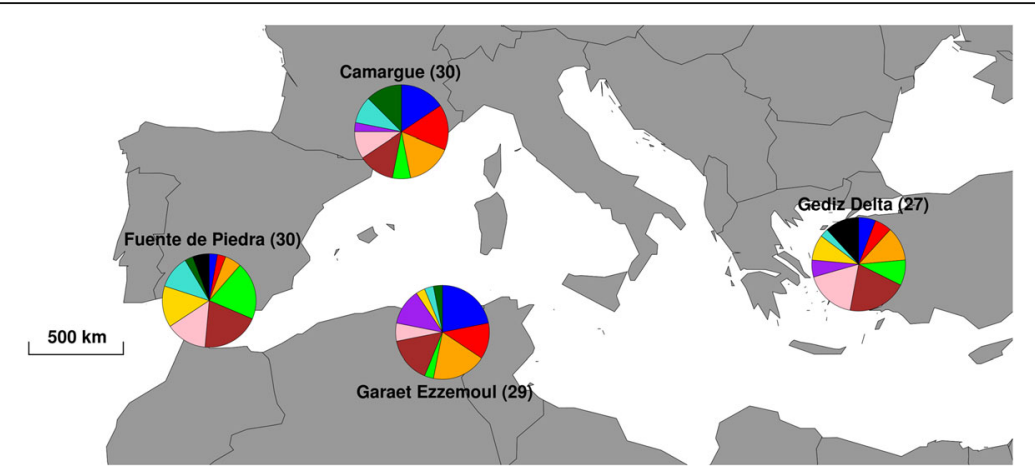

Fig. 1 Pies representing MHC Class IIB exon 2 allele frequencies for alleles with a frequency of at least 10\% within the four studied breeding colonies of the Greater Flamingos across the Mediterranean basin (alleles with a frequency below 10\% are not represented). Each colour represents a different allele

the 267-270 bp of the MHC Class IIB exon 2 was amplified which code for nine positively selected codon sites [21]. Assignment of barcoded sequences to individual barcodes and allele validation was carried out with the aid of SEquence Sorter \& AMplicon Explorer (SESAME) [25]. We used a slightly modified version of Sommer et al.'s [26] pipeline and allele validation followed the following rules: 1) all reads whose length suggested a shift in reading frame during sequencing were discarded; 2) all variants that were represented only once in the run (i.e. singletons) were assumed to be artefacts; 3) we assumed that artefactual variants should occur at lower frequencies than true variants and we used the conservative $T_{2}$ threshold recommended by Galan et al. [27] with $F_{i j}$ of $4 \%$ or above to assign reads as alleles; 4) all sequences that had a 1-2 base pair difference to one of the validated alleles within the sample were assumed to be artefacts; 5) all sequences that had more than a 2 base pair difference from validated alleles and were also validated as alleles if they were classified as alleles in other individuals; 6) the remaining sequences that had more than a 2 base pair difference from a validated allele were validated as alleles only if their frequency exceeded any artefact; 7) we assumed that chimeras were always present together with the true alleles from which they were formed and in lower frequency. Accordingly chimeras were easily identified when reads were aligned within individuals in SESAME and were discarded if in lower frequency than source validated alleles. Gillingham et al. [21] reported a maximum of 4 alleles per individual suggesting two loci for this marker [21]. Of the 126 individuals genotyped, we used in subsequent analyses the 116 for which the authors achieved a $99.9 \%$ confidence in allele calling ( $>300$ reads per individual) (see Gillingham et al. [21] for details of allele calling and simulations). Based on 10 duplicates and 2 triplicates Gillingham et al. [21] found a repeatability of $100 \%$ in allele calling.

\section{Population differentiation analyses}

First, we estimated nucleotide diversity and number of segregating sites using DnaSP version 5 [28]. Second, we measured MHC population differentiation. There are many measures of population differentiation and ways of partitioning genetic variance, with constant debate and research among population geneticists about which measure is the best to use in which circumstance [29-33]. Multilocus genes such as the MHC add the additional complication that their complex nature often violates assumptions required to apply several of these methods (e.g. Hardy-Weinberg equilibrium, linkage disequilibrium, mixed inheritance patterns). A further complication arises

Table 1 Summary statistics of MHC Class IIB exon 2 variation for the four breeding colonies of Greater Flamingos

\begin{tabular}{|c|c|c|c|c|c|c|c|c|c|c|}
\hline Sampling site & $\begin{array}{l}\text { Year of } \\
\text { sampling }\end{array}$ & $N$ & $m$ & $\pi( \pm \mathrm{SD})$ & $S$ & $\begin{array}{l}\text { Mean \# alleles } \\
\text { per individual }\end{array}$ & $\begin{array}{l}\text { Mean } A A_{\text {dist }} \\
( \pm \text { SE })\end{array}$ & $\begin{array}{l}\text { Mean } \mathrm{AA}_{\text {distSelect }} \\
( \pm \mathrm{SE})\end{array}$ & Private alleles & APD $( \pm$ SE $)$ \\
\hline Algeria & $2008 \& 2009$ & 29 & 56 & $0.107( \pm 0.003)$ & 64 & $3.34( \pm 0.15)$ & $0.237( \pm 0.005)$ & $0.641( \pm 0.016)$ & 8 & $94.33( \pm 2.56)$ \\
\hline France & 1998 & 30 & 63 & $0.107( \pm 0.002)$ & 65 & $3.47( \pm 0.11)$ & $0.236( \pm 0.004)$ & $0.633( \pm 0.013)$ & 12 & $95.52( \pm 2.32)$ \\
\hline Spain & 2007 & 30 & 55 & $0.104( \pm 0.003)$ & 66 & $3.43( \pm 0.11)$ & $0.228( \pm 0.004)$ & $0.637( \pm 0.012)$ & 8 & $94.25( \pm 2.53)$ \\
\hline Turkey & $2007 \& 2009$ & 27 & 56 & $0.105( \pm 0.002)$ & 65 & $3.52( \pm 0.13)$ & $0.228( \pm 0.006)$ & $0.647( \pm 0.019)$ & 11 & $93.53( \pm 2.68)$ \\
\hline Total & 1998-2009 & 116 & 109 & $0.105( \pm 0.001)$ & 68 & $3.44( \pm 0.06)$ & $0.233( \pm 0.002)$ & $0.639( \pm 0.007)$ & 39 & $94.50( \pm 1.24)$ \\
\hline
\end{tabular}

$N$ : number of individuals. $m$ : number of alleles. $\pi( \pm S D)$ : population nucleotide diversity and standard deviation. $A A_{\text {dist }}( \pm S E)$ : mean amino acid divergence within individual and standard error of the mean. $A A_{\text {distselect }}( \pm \mathrm{SE})$ : mean amino acid divergence within individual for sites under positive selection according to Gillingham et al. [21] and standard error of the mean. APD ( \pm SE): average per cent difference and standard error of the mean 
when alleles cannot be assigned to loci, as is often the case for MHC datasets in non-model organisms, preventing the identification of heterozygote and homozygote genotypes. As a result, allele frequencies cannot be accurately estimated as the frequency of common alleles is underestimated and that of rare alleles overestimated. We therefore chose to rely on the metric Rho (also known as $p$ statistic) devised by Ronfort et al. [34] for genotype data with multiple alleles per locus in each individual as found in polyploidy species. The Rho statistic is independent of both the ploidy level and the amount of within-individual diversity. This statistic has also recently been demonstrated by simulation to be less biased when assumptions of diploid inheritance are violated than Nei's $\mathrm{G}_{\mathrm{ST}}$ [35], G" ${ }_{\text {ST }}$ [36] and Jost's $D$ [29, 32]. We estimated the Rho statistic in conjunction with traditional Fst [37] to measure MHC population differentiation using the SPAGeDi software [38]. We carried out this analysis on individual MHC Class IIB exon 2 alleles based on the full length nucleotide sequence, allelic lineages based on codon sites which were shown to be under positive selection by Gillingham et al. [21] (i.e. different sequences were considered the same allele if they did not differ in positively selected codon sites) and allelic lineages based on the full length translated amino acid sequences.

When using markers that are highly diverse such as the MHC, many alleles may only be sampled once, even when sample sizes are fairly large, and, in extreme cases, analyses based solely on allele frequencies might be largely ineffective $[39,40]$. Therefore, we also used two other methods to detect genetic differentiation between populations. The first is Hudson's [39] nearest-neighbour statistic $\left(S_{n n}\right)$ which measures how often the "nearest neighbours" of sequences (i.e. the most similar sequence(s) of each sequence) are within the same geographical locality. Sequence similarity is determined as the number of base differences per sequence. For a dataset of sequences collected from $n$ individuals (including identical sequences from different individuals which are the same allele), $S_{n n}$ is estimated as:

$$
S_{n n}=\sum_{j=1}^{n} X_{j} / n
$$

where, $X$ is the number of nearest neighbour belonging to the same geographical locality divided by the total number of nearest neighbour for sequence $j$. Hence, if $X_{j}$ is equal to 1 , then all nearest sequences belonged to individuals sampled within the same geographical locality; and, conversely if $X_{j}$ is equal to 0 , all nearest sequences were from a different geographical locality. In a pairwise comparison between populations, a $S_{n n}$ that is significantly greater than 0.5 therefore indicates evidence of some population structure, as does a global $S_{n n}$ which is significantly greater than 0.25 when simultaneously comparing four populations. The $S_{n n}$ statistic was estimated using the PopGenome package [41] in R and significant departure from predicted values given panmixia were estimated by permutation using 1000 reshuffling in R [42]. We carried out this analysis on both full sequences and on sequences of codon sites which were shown to be under positive selection by Gillingham et al. [21].

The second statistic that we used which does not solely rely on allele frequency was the average percentage difference (APD) which has previously been used in studies investigating MHC population structure [43, 44]. We calculated this statistic as described by Yuhki \& O'Brien [43]. Specifically, APD estimates the average percentage in the number of alleles not shared between two individuals within a population as:

$$
A P D_{k}=\sum_{i=1}^{N}\left(D_{a b} /\left(A_{a}+A_{b}\right)\right)_{i} / N
$$

where for population $k, N$ is the number of pairwise comparisons, $D_{a b}$ is the number of alleles not shared between individual $a$ and individual $b, A_{a}$ and $A_{b}$ are the total number of unique alleles in individuals $a$ and $b$. APD therefore measures within-population genetic variation. We tested whether between breeding colonies APD was significantly different from within breeding colonies APD by permutation using 100,000 reshuffling. APD calculations were performed using R [42].

Finally, we estimated MHC heterozygosity with three metrics that did not require the assignment of $\mathrm{MHC}$ alleles to loci (since this is not possible in our dataset [21]): (i) the number of MHC alleles per individual; (ii) the mean amino acid allele divergence within an individual over the entire translated sequences (of the 163165 bp exon 2 nucleotide sequences; $\mathrm{AA}_{\text {dist }}$ ), and (iii) the mean amino acid allele divergence within an individual over sites found to be under positive selection by Gillingham et al. [21] $\left(\mathrm{AA}_{\text {distSelect }}\right)$. We obtained the proportion of base pair differences between sequences required to compute $\mathrm{AA}_{\text {dist }}$ and $\mathrm{AA}_{\text {distselect }}$ using MEGA 7 [45]. We tested differences in the number of MHC alleles per individual between breeding colonies using a generalized linear model (GLM) with a Poisson distribution and a log link. For testing differences in $\mathrm{AA}_{\text {dist }}$ and $\mathrm{AA}_{\text {distSelect }}$ between breeding colonies we used a GLM model with a binomial distribution (since $\mathrm{AA}_{\text {dist }}$ and $\mathrm{AA}_{\text {distSelect }}$ are averages of proportional data) and a logit link function. All GLMs were fitted in R [42].

\section{Microsatellite genotyping and heterozygosity correlation with MHC Class IIB exon 2}

The 116 samples used for Greater Flamingo MHC Class IIB exon 2 differentiation in this study were previously 
selected for microsatellite genotyping by Geraci et al.[24] for 13 loci: PrA2, PrD3, PrD4, PrD5, PrD7, PrD9, PrA102, PrA110, PrA113, PrC109, PrD108, PrD121 and PrD126. Nine individuals were excluded from this analysis because fewer than 8 microsatellite loci were successfully genotyped for these individuals. In order to compare $\mathrm{MHC}$ differentiation to differentiation at neutral markers we estimated $F_{S T}$ [37] for microsatellite data differentiation as calculated by the SPAGeDi software [38].

\section{Comparison with other avian non-passerine species of MHC Class IIB exon 2 allelic diversity}

In order to compare allelic diversity of greater flamingos with other non-passerine species we searched the literature of other species for which at least 100 individuals were genotyped. We recorded the number of individuals genotyped, the number of loci found (estimated as the number of alleles per individual) and the number of alleles reported. We also calculated the proportion of alleles per individual and the proportion of alleles per individual and loci. We excluded passerines from our study for the following reasons: (1) the evolution and structure of passerine $\mathrm{MHC}$ is completely different from other avian species [46], with passerines having a much higher number of copy number variation [46-50] suggesting that macroevolutionary patterns (i.e. gene duplication history) may lead to very different signals of balancing selection between passerines and other birds [49] and (2) passerines have a large number of pseudogenes which is likely to bias true functional MHC allele diversity and render hazardous a comparison in allelic diversity between passerines and other birds, who tend to have only 2-3 functional loci (Table 2). For example the collared flycatcher, Ficedula albicollis, appears to have at least 9 functional MHC class IIB loci but also appears to have at least $15 \mathrm{MHC}$ class IIB loci that are pseudogenes [47]. However since alleles cannot be assigned to loci in almost all MHC passerine studies, alleles that appear functional (no frame shift in sequences or premature stop codon) may in fact be in non-functional loci and vice versa [49].

\section{Results}

As reported in Gillingham et al. [21], we detected a very high diversity of MHC Class IIB exon 2 with 109 alleles at two loci among 116 individuals (Table 2). The mean number of alleles per individual was 3.44 (Table 1), and 63 individuals had 4 alleles (54\%), 42 individuals had 3 (36\%), 10 individuals had 2 (9\%), and 1 individual had 1 (1\%). The number of alleles identified per population was between 55 and 63 identified alleles (Table 1). Out of 109 alleles identified from nucleotide sequences across the four breeding sites, 39 were private alleles
(Table 1), however all of these alleles were rare and only present within either a single individual (34 alleles) or two individuals (5 alleles). The 109 alleles from nucleotides sequences translate into 104 different amino acid sequences. When comparing with other non-passerine avian species, allelic diversity was higher than all species that had been sampled more than greater flamingos $(n>116)$ except for the Eurasian coot (Table 2). When rarefying coot sample size to 116 (resampling 10000 times with no replacement) median number of alleles was 130 (95\% confidence intervals was 119-142). When rarefying the flamingo dataset (resampling 10000 times with no replacement) to the sample of the two species in Table 2 with a smaller dataset, greater flamingo allelic diversity remained much greater than those species ( $n=100$, median number of alleles $=104,95 \%$ confidence intervals $=100-107 ; n=108$, median number of alleles = $107,95 \%$ confidence intervals $=104-109)$.

There was either little or no differentiation (slightly negative values equivalent to zero) between breeding colonies regardless of whether Fst or Rho was investigated (Table $3 \mathrm{a}$ and b) and global Rho and Fst values were very small and not significantly different from 0 (20,000 permutations: $R h o=0.0001, \quad p=0.929 ; \quad$ Fst $=$ $0.0005, p=0.570$ ). Similar results were found when investigating alleles called from sequences of sites under positive selection (Table 3b; global Rho= 0.0007, $p=0.827$; global Fst $=0.0010, p=0.540$ ) and when investigating sequences from amino acid sequences (see Additional file 1: Table S1; global Rho= 0.0005, $p=0.834$; global Fst $=0.0007, p=0.528$ ).

Further supporting no population structure at the MHC Class IIB exon 2, global $S_{n n}$ did not significantly deviate from the predicted value for a panmictic population of 0.25 when analysing full length sequences $\left(S_{n n}=\right.$ $0.239 ; p=0.714$ ) and sequences known to be under positive selection $\left(S_{n n}=0.246 ; p=0.608\right)$. Similarly pairwise comparison between breeding colonies never significantly deviated from the predicted panmictic value of 0.5 (Table 3c). Average percentage difference (APD) was very high suggesting very high within-population MHC variation (Table 1). Furthermore, APD within colony was not significantly different from APD between breeding colonies $(p=0.590)$ and a similar result was found when analysing APD from amino acid sequences $(p=0.493)$. The mean number of alleles per individual $\left(\chi^{2}=\right.$ 0.132; $\mathrm{df}=3 ; p=0.988)$, mean $\mathrm{AA}_{\text {dist }}\left(\chi^{2}=3.069 ; \mathrm{df}=\right.$ $3 ; p=0.381)$ and mean $\mathrm{AA}_{\text {distSelect }}\left(\chi^{2}=0.449 ; \mathrm{df}=3\right.$; $p=0.930)$ were not significantly different between breeding colonies.

\section{Discussion}

To the best of our knowledge, the MHC allelic diversity in greater flamingos is one of the highest reported so far 
Table 2 Number of alleles for MHC Class IIB exon2 relative to the number of loci and individuals genotyped in non-passerine birds reported in the literature with 100 or more individuals genotyped, showing species name (common name and Latin name), number of individuals genotyped in the study, maximum number of loci based on the maximum number alleles found within an individual in the population, number of alleles found in the study, the ratio between number of alleles and number of individuals, the ratio between number of alleles, number of individuals and number of loci, whether the species is migratory and/or long distance disperser and the citation of the study

\begin{tabular}{|c|c|c|c|c|c|c|c|c|}
\hline $\begin{array}{l}\text { Species } \\
\text { (Common name) }\end{array}$ & $\begin{array}{l}\text { Species } \\
\text { (Latin name) }\end{array}$ & $\begin{array}{l}\text { \# of } \\
\text { ind. }\end{array}$ & $\begin{array}{l}\text { \# of } \\
\text { loci }\end{array}$ & $\begin{array}{l}\text { \# of } \\
\text { alleles }\end{array}$ & $\begin{array}{l}\text { \# of alleles } \\
\text { /\# of ind. }\end{array}$ & $\begin{array}{l}\text { \# of alleles } \\
\text { /\# of ind./\# of loci }\end{array}$ & $\begin{array}{l}\text { Migratory/long- } \\
\text { distance disperser }\end{array}$ & Study \\
\hline Greater Flamingo & $\begin{array}{l}\text { Phoenicopterus } \\
\text { roseus }\end{array}$ & 116 & 2 & 109 & 0.940 & 0.470 & Yes & This study \\
\hline Lesser Kestrel & Falco naumanni & 121 & 1 & 103 & 0.851 & 0.851 & Yes & Alcaide et al., 2008 [55] \\
\hline Magellanic Penguin & $\begin{array}{l}\text { Spheniscus } \\
\text { magellanicus }\end{array}$ & 100 & 1 & 45 & 0.450 & 0.450 & Yes & Knafler et al., 2012 [77] \\
\hline Eurasian Coot & Fulica atra & 906 & 3 & 265 & 0.292 & 0.097 & Partially ${ }^{a}$ & Alcaide et al., 2014 [54] \\
\hline Great Snipe & Gallinago media & 175 & 2 & 50 & 0.286 & 0.143 & Yes & Ekblom et al., 2007 [78] \\
\hline $\begin{array}{l}\text { Greater Prairie } \\
\text { Chicken }\end{array}$ & $\begin{array}{l}\text { Tympanuchus } \\
\text { cupido }\end{array}$ & 182 & 2 & 30 & 0.165 & 0.082 & No & Minias et al., 2016 [79] \\
\hline $\begin{array}{l}\text { Leach's Storm } \\
\text { Petrel }\end{array}$ & $\begin{array}{l}\text { Oceanodroma } \\
\text { leucorhoa }\end{array}$ & 188 & 2 & 24 & 0.128 & 0.064 & Yes & Dearborn et al., 2016 [80] \\
\hline Chinese Egret & Egretta eulophotes & 172 & 5 & 20 & 0.116 & 0.023 & Yes & Lei et al., 2016 [81] \\
\hline Grey Partridge & Perdix perdix & 108 & 2 & 12 & 0.111 & 0.056 & No & Promerová et al., 2013 [82] \\
\hline Blakiston's Fish Owl & Bubo blakistoni & 174 & 8 & 19 & 0.109 & 0.014 & No & Kohyama et al., 2015 [83] \\
\hline Red Grouse & Lagopus lagopus & 296 & 3 & 28 & 0.095 & 0.032 & No & Meyer-Lucht et al., 2016 [84] \\
\hline $\begin{array}{l}\text { Attwater's Prairie } \\
\text { Chicken }\end{array}$ & $\begin{array}{l}\text { Tympanuchus } \\
\text { cupido }\end{array}$ & 142 & 2 & 5 & 0.035 & 0.018 & No & Bateson et al., 2016 [85] \\
\hline
\end{tabular}

${ }^{a}$ Not migratory in the studied population but makes nomadic dispersal movements according to changing water levels and seasonal rainfall. Also fully migratory in other parts of the species distribution

(this study \& [21]) relative to the number of individuals genotyped in non-passerine birds, despite the fact that they appear to harbour only two MHC Class IIB loci (Table 2). Only Coots have slightly higher MHC allelic diversity than Greater flamingos, with 130 alleles (95\% confidence intervals was 119-142) compared to the Flamingo's 109 when rarefied to the same sample size, although Coots harbour three loci. Furthermore, the fact that allele calling is based on 163-165 bp of the 267$270 \mathrm{bp}$ exon 2 sequence suggests that we may be slightly underestimating allelic diversity since alleles may differ in regions outside the amplified segment. The variation we found in the number of alleles per individual can be explained by either variation in loci copy number as reported in certain bird species e.g. [51, 52] or balancing selection maintaining identical alleles across duplicated loci e.g. [53]. Alternatively, we cannot exclude that our design of primers was not optimal and may have led to some allele dropout. Indeed designing optimal primers without any allele dropout is notoriously difficult to achieve in non-model organisms [26]. However the latter is unlikely to bias population differentiation analyses since the same primers were used across all individuals and populations.

Passerines frequently appear to also present a very high diversity of MHC alleles [46-50] but this generally seems to be due to their high number of MHC gene copies [49]. Furthermore due to the high number of pseudogenes reported in passerines, unbiased functional allelic diversity of these species is unclear and difficult to quantify. Two other examples of non-passerine bird species with a high allelic MHC diversity are the Eurasian Coot, Fulica atra, [54] (265 alleles; 906 individuals; 3 loci) and the Lesser Kestrel Falco naumanni [55] (103 alleles; 121 individuals; 1 loci). Like Greater Flamingos, the Eurasian Coot has a large geographical distribution and form large populations [54], whilst the colonial Lesser Kestrel is a long distance migratory species and forms small populations [55]. One possibility is that high gene flow across breeding sites in the Mediterranean population of Greater Flamingos is relatively recent and that range-wide $\mathrm{MHC}$ diversity arose through local adaptation. However, we believe the latter to be highly unlikely for the following reason. Geraci et al. [24] have shown that flamingo populations have undergone a bottleneck followed by rapid growth and expansion, with the average time since expansion being estimated to be 696421 yr (90\% CI: 526 316-1 131579 yr), suggesting that high gene flow in this species is not recent. A possible increase in gene flow remains possible since over the last three centuries wetlands and favourable nesting places for flamingos have become scarce [56]. However, 
Table 3 Pairwise Rho statistic [34] of MHC Class IIB Exon 2 for alleles called from full nucleotide sequences (below diagonal) and alleles called from nucleotide sequences of sites under positive section (above diagonal) (a); pairwise $F_{\text {ST }}$ statistic [37] of MHC Class IIB Exon 2 for alleles called from full nucleotide sequences (below diagonal) and alleles called from nucleotide sequences of sites under positive section (above diagonal) (b); pairwise $S_{n n}$ statistic [39] of MHC Class IIB Exon 2 for full length nucleotide sequences (below diagonal) and for nucleotide sequences of sites under positive section (above diagonal) (b) and, pairwise $F_{S T}$ values for 13 microsatellite loci (above diagonal) for four breeding colonies of Greater Flamingos across the Mediterranean basin

\begin{tabular}{|c|c|c|c|c|}
\hline & Algeria & France & Spain & Turkey \\
\hline \multicolumn{5}{|c|}{ a. Rho statistic for MHC Class IIB exon 2} \\
\hline Algeria & & -0.0018 & 0.0137 & -0.0003 \\
\hline France & -0.0049 & & 0.0002 & -0.0016 \\
\hline Spain & 0.0135 & 0.0038 & & -0.0075 \\
\hline Turkey & -0.0018 & -0.0017 & -0.0096 & \\
\hline \multicolumn{5}{|c|}{ b. $F_{S T}$ statistic for MHC Class IIB exon 2} \\
\hline Algeria & & -0.0012 & 0.0043 & 0.0006 \\
\hline France & -0.0020 & & -0.0001 & 0.0008 \\
\hline Spain & 0.0045 & 0.0010 & & -0.0007 \\
\hline Turkey & 0.0006 & 0.0007 & -0.0014 & \\
\hline \multicolumn{5}{|c|}{ c. $S_{n n}$ statistic for MHC Class IIB exon 2} \\
\hline Algeria & & 0.494 & 0.524 & 0.480 \\
\hline France & 0.494 & & 0.503 & 0.504 \\
\hline Spain & 0.533 & 0.489 & & 0.489 \\
\hline Turkey & 0.515 & 0.498 & 0.475 & \\
\hline \multicolumn{5}{|c|}{ d. $F_{S T}$ statistic for 13 microsatellite locus } \\
\hline \multicolumn{5}{|l|}{ Algeria } \\
\hline France & 0.0062 & & & \\
\hline Spain & 0.0042 & 0.0063 & & \\
\hline Turkey & -0.0027 & -0.0020 & -0.0020 & \\
\hline
\end{tabular}

Note that all the Rho and $F_{S T}$ statistic values are close to zero (negative values are equivalent to 0 ). None of the differentiation values were significantly different from 0 regardless of the statistic (Rho or $F_{S T}$ ) or the marker investigated (MHC Class IIB exon 2 or microsatellite markers). Similarly none of the $S_{n n}$ statistic values were significantly different from 0.5 , the predicted value of panmixia between two populations

there is no reason to believe that the species was less nomadic in the ancient past than today. Our study therefore supports that in Greater Flamingos, although high dispersal rates disrupts the local adaptation mechanisms that are predicted to maintain MHC diversity, pathogen-mediated balancing selection at the scale of the large and panmictic Mediterranean population is sufficiently strong to generate high MHC allelic diversity. However, a greater characterisation of MHC diversity of migratory and non-migratory bird species than is currently available in the literature, followed by a metaanalysis, would be required to formally test whether ecology and life history traits of species (such as migration, long distance dispersal, wide geographic distribution and colonial breeding) predicts population wide $\mathrm{MHC}$ allelic diversity.

Theory predicts that local adaptation and divergent selection between populations should be favoured when gene flow is at an intermediate level [23]. Such intermediate levels of gene flow may occur between breeding sites of colonial breeding species if philopatric behaviour is coupled with regular dispersal [57]. In lesser kestrels, pathogen-mediated balancing selection at the local scale of the population appears to be maintaining high allelic diversity (stronger local population structure at MHC markers than at neutral makers) [55]. A similar result was reported in the migratory but philopatric loggerhead sea turtles (Caretta caretta) which showed distinct MHC differentiation between breeding colonies, despite close proximity between sites $(80-260 \mathrm{~km})$ [58]. However, evidence that local adaptation can occur despite high gene flow has only been reported in a few studies of marine fish [59-62]. It is also worth noting that we could find no evidence of temporal variation in $\mathrm{MHC}$ allele frequency. The Greater Flamingo colony in France was sampled 9-11 years prior to other breeding colonies in our study. The slow reproductive rate of flamingos means that this represents approximately a difference of a single generation with other breeding colonies [22]. Indeed, Pradel et al. [63] demonstrated that at age 10, virtually all individuals had attempted to breed at least once and about $90 \%$ of them have already done so at age 9. Thus our results tentatively suggests that allele frequency does not significantly shift during this short time period as reported in species with faster reproductive rates [8]. However more generations from the same geographical locality are needed to confirm the latter. Nonetheless, in the case of Greater Flamingos in the Mediterranean basin, given the lack of spatial MHC population structure, high allelic MHC diversity appears to be maintained by overdominant heterozygote advantage and/ or population wide frequency dependent selection rather than local fluctuating selection and/or local variation in frequency dependent selection.

The lack of locally adapted alleles may be explained by gene swamping, whereby specific local polymorphism is lost because gene flow is larger than selection [64]. Furthermore, for local population structure at the MHC to occur there needs to be strong spatial variation in parasite communities [5]. While Greater Flamingos occupy a large diversity of wetland habitats across the Mediterranean, the parasite communities that flamingos encounter remain by and large unknown. However, a strong driver of MHC class IIB are likely to be the multiple species of helminths that Greater Flamingos are known to be parasitized by [65], with artemia species 
consumed by Greater Flamingos known to be the intermediate host [66]. Indeed parasitic helminths are known to cause significant pathology in birds which can result in lower fat content [67], increased chick mortality [68] and lower reproductive success [69]. Furthermore, migratory species are known to harbour a larger diversity of nematodes [14, 15], in particular species with wide geographic distributions and using multiple aquatic habitats [14] such as is the case for Greater Flamingos. It is therefore possible that flamingos do encounter a strong variation of parasites at different sites in the Mediterranean, but significant breeding dispersal [22, 70] leads to sufficiently strong gene flow to disrupt any possible local adaptation. In this case, dispersal may also enable Greater Flamingos to escape from locally prevalent pathogens that are highly adapted to the hosts.

Alternatively, the high dispersal rates of flamingos may act to facilitate the dispersal of parasites themselves, and, hence, homogenise parasite communities across the Mediterranean. Furthermore it has been suggested that saline wetlands may harbour fewer parasites than freshwater wetlands [71]. For example, Mendes et al. [72] found that species of wading birds inhabiting saline habitats had fewer blood parasite infections than species from freshwater habitats. Indeed, despite the screening of chicks, studies have never detected blood parasites in Greater Flamingos in the Mediterranean [56, 73]. Regarding helminths, a comparative study by Poulin [74] using data from 389 parasitic species of cestodes, trematodes and nematodes in 158 bird species found that a positive correlation between heavy infections in local host populations and the ability to exploit many host species. The latter is suggestive that helminth infections that affect most fitness may be widespread rather than locally constrained. Therefore, the diversity and heterogeneity of parasites encountered by flamingos may be comparatively low and, in turn, the cost of dispersing, in terms of encountering new parasites that they are not immune to, may also be comparatively lower than for inland species. Indeed, the high dispersal rates encountered in Greater Flamingos are on par with the ones found in marine colonial birds that tend to have a higher dispersal rates than other migratory avian species (reviewed in [75]). In the absence of local variation in parasite communities, the benefits of dispersing, such as finding alternative breeding and feeding sites to avoid high competition at the natal site (especially for young inexperienced birds), may outweigh the costs.

\section{Conclusion}

Regardless of whether parasites vary across time and space in flamingos, the very high diversity of MHC Class IIB alleles observed in this study suggests strong pathogen-mediated balancing selection at the scale of the whole population. Given the lack of local MHC population structure, MHC diversity appears to be maintained by overdominant heterozygote advantage and/or population wide frequency dependent selection rather than local fluctuating selection and/or local variation in frequency dependent selection. Further understanding of how pathogens vary across space and time will be crucial to further elucidate the mechanisms maintaining $\mathrm{MHC}$ diversity in large panmictic populations with high dispersal rates [5].

\section{Additional file}

Additional file 1: Table S1. Pairwise Rho statistic [34] (a) and pairwise $F_{S T}$ statistic [37] of MHC Class IIB Exon 2 for alleles called from amino acid sequences for four breeding colonies of Greater Flamingos across the Mediterranean basin. (DOCX 18 kb)

\section{Acknowledgements \\ We are deeply grateful to the late Luc Hoffmann and the late Alan Johnson for the instigation of the long-term study on the Greater Flamingo. We warmly thank all the people who participated in collecting genetic samples of Greater Flamingos and in particular Christophe Germain and Antoine Arnaud. We thank Christine Dubreuil and Maria Teixeira for laboratory assistance. We thank Miguel Alcaide for kindly providing coot MHC genotype data for the rarefied analysis.}

\section{Funding}

This study was funded by the TOTAL foundation, the Conseil Régional de Bourgogne, the MAVA foundation, the Centre National de la Recherche Scientifique (CNRS), and the German Science Foundation (DFG Gi 1065/2-1).

\section{Availability of data and materials}

The data set (Flamingo MHC Class IIB exon 2 genotype data) supporting the results of this article is available in the Dryad repository, doi:10.5061/dryad.p65s2 [76].

\section{Authors' contributions}

$M G, A B, S S$ and $F C$ conceived/designed the study. MG conducted all laboratory work. FC, AB, MR., JA, BS and OO organised the field work and/or provided the samples used in this study. MG wrote the first draft of the paper and all authors contributed to subsequent versions. MG and AC analysed and interpreted the data. All authors gave final approval for publication and agree to be held accountable for the work performed.

\section{Competing interests}

The authors declare that they have no competing interests.

\section{Ethics approval and consent to participate}

Ringing and sample collection of greater flamingo chicks in France were authorised through the personal permit (number 405) of Alan Johnson and Arnaud Béchet delivered by the Centre de Recherche sur la Biologie des Populations d'Oiseaux (CRBPO, Muséum national d'histoire naturelle, France). The study protocol was reviewed and approved by the CRBPO. Ringing and sample collection of greater flamingo chicks in Turkey were authorised through the personal ringing licence (Certificate number $=1$ ) of Ortaç Onmuş and ringing licences of various Turkish bird ringers (who have participated to the ringing studies) by the General Directorate of National Parks of the Ministry of Forestry and Water Works of the Republic of Turkey. All the studies of ringing and sample collection in Turkey were applied under the surveillance of and approved by the General Directorate of National Parks. Boudjéma Samraoui was authorised to sample and ring flamingo chicks through the Algerian Ministère de l'Enseignement Supérieur et de la Recherche Scientifique (MESRS). The Consejería de Medio Ambiente of the Junta de Andalucía (Regional Government) authorised the ringing and sampling of flamingo chicks in Spain. 


\section{Author details}

'University of Ulm, Institute of Evolutionary Ecology and Conservation Genomics, Albert-Einstein Allee 11, D-89069 Ulm, Germany. ${ }^{2}$ Université de Bourgogne, Equipe Ecologie Evolutive, UMR CNRS 6282 Biogéosciences, 6 bd. Gabriel, 21000 Dijon, France. ${ }^{3}$ Centre de Recherche de la Tour du Valat, Le Sambuc, 13200 Arles, France. ${ }^{4}$ Leibniz Institute for Zoo and Wildlife Research, Evolutionary Genetics, Alfred-Kowalke-Str. 17, D-10315 Berlin, Germany. ${ }^{5}$ Berlin Center for Genomics in Biodiversity Research (BeGenDiv), D-14195 Berlin, Germany. ${ }^{6}$ R.N. Laguna de Fuente de Piedra, Consejería de Medio Ambiente y Ordenación del Territorio, Junta de Andalucía, Apartado 1, E-29520 Fuente de Piedra, (Málaga), Spain. ' Department of Wetland Ecology, Estación Biológica de Doñana, (EBD-CSIC), calle Américo Vespucio s/ n, E-41092 Sevilla, Spain. ${ }^{8}$ Natural History Museum, Faculty of Sciences, Department of Biology, Ege University, Bornova, İmir, Turkey. ${ }^{9}$ Center of Excellence for Research in Biodiversity, King Saud University, Riyadh, Saudi Arabia. ${ }^{10}$ Laboratoire de recherche et de conservation des zones humides, University of Guelma, Guelma, Algeria. ${ }^{11}$ Institut Universitaire de France, Paris, France.

Received: 29 September 2016 Accepted: 6 February 2017 Published online: 20 February 2017

\section{References}

1. Reed DH, Frankham R. Correlation between Fitness and Genetic Diversity. Conserv Biol. 2003;17:230-7.

2. Willi Y, Van Buskirk J, Hoffmann AA. Limits to the adaptive potential of small populations. Annu Rev Ecol Evol Syst. 2006;37:433-58.

3. Janeway CA, Travers P, Walport M, Shlomchik MJ. Immunobiology: the immune system in health and disease. London: Garland Sience; 2005.

4. Sommer $\mathrm{S}$. The importance of immune gene variability $(\mathrm{MHC})$ in evolutionary ecology and conservation. Front Zool. 2005;2:16.

5. Spurgin LG, Richardson DS. How pathogens drive genetic diversity: MHC, mechanisms and misunderstandings. Proc Biol Sci. 2010;277:979-88.

6. Westerdahl $\mathrm{H}$. No evidence of an $\mathrm{MHC}$-based female mating preference in great reed warblers. Mol Ecol. 2004;13:2465-70.

7. Bryja J, Charbonnel N, Berthier K, Galan M, Cosson J-F. Density-related changes in selection pattern for major histocompatibility complex genes in fluctuating populations of voles. Mol Ecol. 2007;16:5084-97.

8. Eizaguirre C, Lenz TL, Kalbe M, Milinski M. Rapid and adaptive evolution of $\mathrm{MHC}$ genes under parasite selection in experimental vertebrate populations. Nat Commun. 2012;3:621.

9. Hill AVS. HLA Associations with Malaria in Africa: Some Implications for MHC Evolution. In: Klein J, Klein D, editors. Mol. Evol. Major Histocompat. Complex [Internet]. Springer Berlin Heidelberg; 1991 [cited 2013 Jul 25]. p. 403-20. Available from: http://link.springer.com/chapter/10.1007/978-3-642-84622-9_33

10. Clarke B, Kirby DRS. Maintenance of Histocompatibility Polymorphisms. Nature. 1966;211:999-1000.

11. Snell $\mathrm{G}$. The $\mathrm{H}-2$ locus of the mouse: observations and speculations concerning its comparative genetics and its polymorphism. Folia Biol (Praha). 1968;14(5):335-58.

12. Bodmer WF. Evolutionary Significance of the HL-A System. Nature. 1972;237:139-83.

13. Altizer S, Bartel R, Han BA. Animal Migration and Infectious Disease Risk. Science. 2011;331:296-302.

14. Leung TLF, Koprivnikar J. Nematode parasite diversity in birds: the role of host ecology, life history and migration. J Anim Ecol. 2016;85:1471-80.

15. Koprivnikar J, Leung TLF. Flying with diverse passengers: greater richness of parasitic nematodes in migratory birds. Oikos. 2015;124:399-405.

16. Poulin R, Morand S. Parasite Biodiversity. Washington: Smithsonian Books; 2004.

17. Gregory RD. Parasites and Host Geographic Range as Illustrated by Waterfowl. Funct Ecol. 1990;4:645-54.

18. Minias $P$, Whittingham LA, Dunn PO. Coloniality and migration are related to selection on MHC genes in birds. Evolution. 2017;71:432-41.

19. Takahata N, Nei M. Allelic genealogy under overdominant and frequencydependent selection and polymorphism of major histocompatibility complex loci. Genetics. 1990;124:967-78.

20. McClelland EE, Penn DJ, Potts WK. Major Histocompatibility Complex Heterozygote Superiority during Coinfection. Infect Immun. 2003;71:2079-86.
21. Gillingham MAF, Courtiol A, Teixeira M, Galan M, Bechet A, Cezilly F. Evidence of gene orthology and trans-species polymorphism, but not of parallel evolution, despite high levels of concerted evolution in the major histocompatibility complex of flamingo species. J Evol Biol. 2016;29:438-54.

22. Balkız Ö, Béchet A, Rouan L, Choquet R, Germain C, Amat JA, et al. Experience-dependent natal philopatry of breeding greater flamingos. J Anim Ecol. 2010;79:1045-56.

23. Garant D, Forde SE, Hendry AP. The multifarious effects of dispersal and gene flow on contemporary adaptation. Funct Ecol. 2007;21:434-43.

24. Geraci J, Béchet A, Cézilly F, Ficheux S, Baccetti N, Samraoui B, et al. Greater flamingo colonies around the Mediterranean form a single interbreeding population and share a common history. J Avian Biol. 2012;43:341-54.

25. Meglécz E, Piry S, Desmarais E, Galan M, Gilles A, Guivier E, et al. SESAME (SEquence Sorter \& AMplicon Explorer): genotyping based on high-throughput multiplex amplicon sequencing. Bioinforma Oxf Engl. 2011;27:277-8.

26. Sommer S, Courtiol A, Mazzoni CJ. MHC genotyping of non-model organisms using next-generation sequencing: a new methodology to deal with artefacts and allelic dropout. BMC Genomics. 2013;14:542.

27. Galan M, Guivier E, Caraux G, Charbonnel N, Cosson J-F. A 454 multiplex sequencing method for rapid and reliable genotyping of highly polymorphic genes in large-scale studies. BMC Genomics. 2010;11:296.

28. Librado P, Rozas J. DnaSP v5: a software for comprehensive analysis of DNA polymorphism data. Bioinformatics. 2009;25:1451-2.

29. Jost L. GST and its relatives do not measure differentiation. Mol Ecol. 2008;17:4015-26.

30. Meirmans PG, Hedrick PW. Assessing population structure: FST and related measures. Mol Ecol Resour. 2011;11:5-18.

31. Whitlock MC. G' STand D do not replace FST. Mol Ecol. 2011;20:1083-91.

32. Meirmans PG, Van Tienderen PH. The effects of inheritance in tetraploids on genetic diversity and population divergence. Heredity. 2013;110:131-7.

33. Dufresne F, Stift M, Vergilino R, Mable BK. Recent progress and challenges in population genetics of polyploid organisms: an overview of current state-ofthe-art molecular and statistical tools. Mol Ecol. 2014;23:40-69.

34. Ronfort J, Jenczewski E, Bataillon T, Rousset F. Analysis of Population Structure in Autotetraploid Species. Genetics. 1998;150:921-30.

35. Nei M. Molecular evolutionary genetics. New York: Columbia University Press; 1987.

36. Hedrick PW. A Standardized Genetic Differentiation Measure. Evolution. 2005;59:1633-8

37. Weir BS, Cockerham CC. Estimating F-Statistics for the Analysis of Population Structure. Evolution. 1984:38:1358-70.

38. Hardy OJ, Vekemans X. spagedi: a versatile computer program to analyse spatial genetic structure at the individual or population levels. Mol Ecol Notes. 2002;2:618-20.

39. Hudson RR. A new statistic for detecting genetic differentiation. Genetics. 2000;155:2011-4.

40. Hudson RR, Boos DD, Kaplan NL. A statistical test for detecting geographic subdivision. Mol Biol Evol. 1992;9:138-51.

41. Pfeifer B, Wittelsbürger U, Onsins SER, Lercher MJ. PopGenome: An efficient swiss army knife for population genomic analyses in R. Mol Biol Evol. 2014;31(7):1929-36.

42. Core Team R. R: A language and environment for statistical computing. Vienna: R Foundation for Statistical Computing [Internet]; 2016. Available from: http://www.R-project.org/.

43. Yuhki N, O'Brien SJ. DNA variation of the mammalian major histocompatibility complex reflects genomic diversity and population history. Proc Natl Acad Sci. 1990;87:836-40.

44. Miller HC, Allendorf F, Daugherty $\mathrm{CH}$. Genetic diversity and differentiation at $\mathrm{MHC}$ genes in island populations of tuatara (Sphenodon spp.). Mol Ecol. 2010;19:3894-908.

45. Kumar S, Stecher G, Tamura K. MEGA7: Molecular Evolutionary Genetics Analysis version 7.0 for bigger datasets. Mol Biol Evol. 2016;33(7):1870-4.

46. Bollmer JL, Ruder EA, Johnson JA, Eimes JA, Dunn PO. Drift and selection influence geographic variation at immune loci of prairie-chickens. Mol Ecol. 2011;20:4695-706.

47. Zagalska-Neubauer M, Babik W, Stuglik M, Gustafsson L, Cichoń M, Radwan J. 454 sequencing reveals extreme complexity of the class II Major Histocompatibility Complex in the collared flycatcher. BMC Evol Biol. 2010;10:395.

48. Sepil I, Moghadam HK, Huchard E, Sheldon BC. Characterization and 454 pyrosequencing of Major Histocompatibility Complex class I genes in the great tit reveal complexity in a passerine system. BMC Evol Biol. 2012;12:68. 
49. O'Connor EA, Strandh M, Hasselquist D, Nilsson J-å, Westerdahl H. The Evolution of Highly Variable Immunity Genes Across a Passerine Bird Radiation. Mol Ecol. 2016;25(4):977-89.

50. Alcaide M, Liu M, Edwards SV. Major histocompatibility complex class evolution in songbirds: universal primers, rapid evolution and base compositional shifts in exon 3. PeerJ. 2013;1:e86.

51. Eimes JA, Bollmer JL, Whittingham LA, Johnson JA, Van Oosterhout C, Dunn PO. Rapid loss of MHC class II variation in a bottlenecked population is explained by drift and loss of copy number variation. J Evol Biol. 2011;24:1847-56

52. Strandh M, Westerdahl H, Pontarp M, Canbäck B, Dubois M-P, Miquel C, et al. Major histocompatibility complex class II compatibility, but not class I, predicts mate choice in a bird with highly developed olfaction. Proc R Soc B Biol Sci. 2012;279:4457-63.

53. Worley K, Gillingham M, Jensen P, Kennedy LJ, Pizzari T, Kaufman J, et al. Single locus typing of MHC class I and class II B loci in a population of red jungle fowl. Immunogenetics. 2008;60:233-47.

54. Alcaide M, Muñoz J, Martínez-de la Puente J, Soriguer R, Figuerola J. Extraordinary MHC class II B diversity in a non-passerine, wild bird: the Eurasian Coot Fulica atra (Aves: Rallidae). Ecol Evol. 2014;4:688-98.

55. Alcaide M, Edwards SV, Negro JJ, Serrano D, Tella JL. Extensive polymorphism and geographical variation at a positively selected MHC class II B gene of the lesser kestrel (Falco naumanni). Mol Ecol. 2008;17:2652-65.

56. Johnson A, Cézilly FC. The Greater Flamingo. Poyser; 2007.

57. Friesen VL, Burg TM, McCOY KD. Mechanisms of population differentiation in seabirds. Mol Ecol. 2007;16:1765-85.

58. Stiebens VA, Merino SE, Roder C, Chain FJJ, Lee PLM, Eizaguirre C. Living on the edge: how philopatry maintains adaptive potential. Proc R Soc B Biol Sci. 2013;280:20130305.

59. Nielsen EE, Hemmer-Hansen J, Poulsen NA, Loeschcke V, Moen T, Johansen $T$, et al. Genomic signatures of local directional selection in a high gene flow marine organism; the Atlantic cod (Gadus morhua). BMC Evol Biol. 2009;9:276.

60. André C, Larsson LC, Laikre L, Bekkevold D, Brigham J, Carvalho GR, et al. Detecting population structure in a high gene-flow species, Atlantic herring (Clupea harengus): direct, simultaneous evaluation of neutral vs putatively selected loci. Heredity. 2011;106:270-80.

61. DeFaveri J, Merilä J. Evidence for adaptive phenotypic differentiation in Baltic Sea sticklebacks. J Evol Biol. 2013;26:1700-15.

62. DeFaveri J, Jonsson PR, Merilä J. Heterogeneous Genomic Differentiation in Marine Threespine Sticklebacks: Adaptation Along an Environmental Gradient. Evolution. 2013;67:2530-46.

63. Pradel R, Johnson AR, Viallefont A, Nager RG, Cézilly F. Local Recruitment in the Greater Flamingo: A New Approach Using Capture- Mark-Recapture Data. Ecology. 1997;78:1431.

64. Lenormand T. Gene flow and the limits to natural selection. Trends Ecol Evol. 2002;17:183-9.

65. Robert F, Gabrion C. Cestodoses de l'avifaune camarguaise. Rôle d'Artemia (Crustacea, Anostraca) et stratégies de rencontre hôte-parasite. Ann Parasitol Hum Comparée. 1991;66:226-35.

66. Sánchez MI, Nikolov PN, Georgieva DD, Georgiev BB, Vasileva GP, Pankov P, et al. High prevalence of cestodes in Artemia spp. throughout the annual cycle: relationship with abundance of avian final hosts. Parasitol Res. 2013;112:1913-23.

67. Shutler D, Alisauskas RT, Daniel MLJ. Associations between body composition and helminths of lesser snow geese during winter and spring migration. Int J Parasitol. 2012;42:755-60.

68. Souchay G, Gauthier G, Pradel R. Temporal variation of juvenile survival in a long-lived species: the role of parasites and body condition. Oecologia. 2013;173:151-60.

69. Saumier MD, Rau ME, Bird DM. The effect of Trichinella pseudospiralis infection on the reproductive success of captive American kestrels (Falco sparverius). Can J Zool. 1986;64:2123-5.

70. Nager RG, Johnson AR, Boy V, Rendon-Martos M, Calderon J, Cézilly F. Temporal and spatial variation in dispersal in the greater flamingo (Phoenicopterus ruber roseus). Oecologia. 1996;107:204-11.

71. Piersma T. Do Global Patterns of Habitat Use and Migration Strategies CoEvolve with Relative Investments in Immunocompetence due to Spatial Variation in Parasite Pressure? Oikos. 1997;80:623.
72. Mendes L, Piersma T, Lecoq M, Mendes L, Piersma T, Lecoq M, Spaans BE, Ricklefs R. Disease-limited distributions? Contrasts in the prevalence of avian malaria in shorebird species using marine and freshwater habitats. Oikos. 2005:109:396-404.

73. Ashford R, Cezilly F, Hafner H, Gory G. Scarcity of haematozoa in some colonial birds in southern France. Ekologija. 1994;4:33-5.

74. Poulin R. The intra- and interspecific relationships between abundance and distribution in helminth parasites of birds. J Anim Ecol. 1999;68:719-25.

75. Møller AP, Szép T. The role of parasites in ecology and evolution of migration and migratory connectivity. J Ornithol. 2011;152:141-50.

76. Gillingham M, Béchet A, Courtiol A, Rendón-Martos M, Amat JA, Samraoui B, et al. Data from: Very high MHC Class IIB diversity without spatial differentiation in the Mediterranean population of greater flamingos. Dryad Digital Repository. http://dx.doi.org/10.5061/dryad.p65s2. 2017.

77. Knafler GJ, Clark JA, Boersma PD, Bouzat JL. MHC Diversity and Mate Choice in the Magellanic Penguin, Spheniscus magellanicus. J Hered. 2012;103(6):759-68.

78. Ekblom R, Sæther SA, Jacobsson P, Fiske P, Sahlman T, Grahn M, et al. Spatial pattern of MHC class II variation in the great snipe (Gallinago media). Mol Ecol. 2007;16:1439-51.

79. Minias P, Bateson ZW, Whittingham LA, Johnson JA, Oyler-McCance S, Dunn PO. Contrasting evolutionary histories of MHC class I and class II loci in grouse-effects of selection and gene conversion. Heredity. 2016;116:466-76.

80. Dearborn DC, Gager AB, McArthur AG, Gilmour ME, Mandzhukova E, Mauck RA. Gene duplication and divergence produce divergent MHC genotypes without disassortative mating. Mol Ecol. 2016;25:4355-67.

81. Lei W, Fang W, Zhou X, Lin Q, Chen X. Population genetic diversity and geographical differentiation of MHC class II DAB genes in the vulnerable Chinese egret (Egretta eulophotes). Conserv. Genet. 2016;1-10.

82. Promerová M, Králová T, Bryjová A, Albrecht T, Bryja J. MHC Class IIB Exon 2 Polymorphism in the Grey Partridge (Perdix perdix) Is Shaped by Selection, Recombination and Gene Conversion. PLoS ONE. 2013;8:e69135.

83. Kohyama TI, Omote K, Nishida C, Takenaka T, Saito K, Fujimoto S, et al. Spatial and temporal variation at major histocompatibility complex class IIB genes in the endangered Blakiston's fish owl. Zool Lett. 2015;1:13.

84. Meyer-Lucht Y, Mulder KP, James MC, McMahon BJ, Buckley K, Piertney SB, et al. Adaptive and neutral genetic differentiation among Scottish and endangered Irish red grouse (Lagopus lagopus scotica). Conserv Genet. 2016;17:615-30.

85. Bateson ZW, Hammerly SC, Johnson JA, Morrow ME, Whittingham LA, Dunn PO. Specific alleles at immune genes, rather than genome-wide heterozygosity, are related to immunity and survival in the critically endangered Attwater's prairie-chicken. Mol Ecol. 2016;25:4730-44.

\section{Submit your next manuscript to BioMed Central and we will help you at every step:}

- We accept pre-submission inquiries

- Our selector tool helps you to find the most relevant journal

- We provide round the clock customer support

- Convenient online submission

- Thorough peer review

- Inclusion in PubMed and all major indexing services

- Maximum visibility for your research

Submit your manuscript at www.biomedcentral.com/submit 